\title{
What Would Digital Early Intervention for Bipolar Disorder Look Like? Theoretical and Translational Considerations for Future Therapies
}

\author{
Greg Murray* \\ Centre for Mental Health, Swinburne University of Technology, Melbourne, VIC, Australia
}

There are growing calls for the development of early intervention/preventive interventions for young people identified to be at risk of bipolar disorder (BD), and digital delivery appears to be a strong candidate delivery method. To date, no such interventions exist, and the aim of this perspective paper is to advance the literature by reviewing theoretical issues related to early intervention in $\mathrm{BD}$ and introducing a framework for design of feasible, acceptable, and effective online psychosocial interventions for this population. It

\section{OPEN ACCESS}

Edited by:

Heleen Riper,

Vrije Universiteit Amsterdam,

Netherlands

Reviewed by:

Victoria E. Cosgrove,

Stanford University,

United States

Alyson Dodd,

Northumbria University,

United Kingdom

*Correspondence:

Greg Murray

gwm@swin.edu.au

Specialty section:

This article was submitted to

Child and Adolescent Psychiatry,

a section of the journal

Frontiers in Psychiatry

Received: 11 March 2019

Accepted: 29 July 2019

Published: 23 August 2019

Citation:

Murray G (2019) What Would Digital Early Intervention for Bipolar

Disorder Look Like? Theoretical and Translational Considerations for

Future Therapies.

Front. Psychiatry 10:599.

doi: 10.3389/fpsyt.2019.00599 is concluded that, by adopting an appropriate transdiagnostic and humanistic framework, and recognizing emerging tenets of digital psychotherapy development, testable online interventions for young people at risk of $\mathrm{BD}$ are within reach.

Keywords: engagement, agency, transdiagnostic, online, smartphone, staging, co-design, resilience

Bipolar disorder (BD) is a serious mental illness affecting half a million Australians (1) and $2-3 \%$ of the world's population (2). Prominent commentators are calling for the development of early intervention/preventive approaches to mitigate the significant morbidity and mortality associated with BD [e.g., Refs. (3-5)]. ${ }^{1}$ Digital delivery platforms are receiving growing attention for established $\mathrm{BD}$ [e.g., Refs. (6-10)] but have not yet been applied in the early intervention domain. The aim of this paper is to take the next step toward online early intervention for BD by doing some prerequisite conceptual work. Firstly, existing data relevant to the potential of digital early intervention in $\mathrm{BD}$ are briefly summarized. Secondly, theoretical considerations for early intervention in BD are introduced, leading to three assertions about the optimal approach for those at elevated risk of BD. Finally, translational considerations are canvassed in a novel intervention design framework, the final stage of which is a co-design process with consumers.

\section{DIGITAL EARLY INTERVENTION FOR BIPOLAR DISORDER: SOME RELEVANT DATA}

To date, no digital early interventions have been developed for populations at risk of BD. However, triangulated findings from three cognate literatures suggest that digital platforms have potential as a modality for early psychological intervention in BD. Firstly, there is meta-analytic evidence that effective psychological treatments for young people with, and at risk for, major depressive disorder can

\footnotetext{
${ }^{1}$ For the present purposes, the phrase "early intervention" is preferred over "prevention" because a) from a staging perspective, people with elevated risk of a future diagnosis of $\mathrm{BD}$ (through, e.g., family history and nonspecific symptoms) can be viewed as being on the developmental spectrum of $\mathrm{BD}$, and $\mathrm{b}$ ) the goals of optimal intervention in this population are much broader than prevention of a future specific BD diagnosis.
} 
be effectively and safely delivered digitally [see Refs. (11-13)]. In a recent review, Hollis and colleagues note that many questions remain in this nascent literature but conclude that digital health interventions hold "huge potential for widening access, increasing efficiency and improving healthcare outcomes" (14, p. 498). Secondly, a recent systematic review of early intervention for BD identified seven studies of face-to-face psychological treatments (15), with broadly positive findings for a range of outcomes. The existing literature has significant limitations, however: only two randomized controlled trials have been published, and the majority of studies have simply translated treatments for established $\mathrm{BD}$, rather than testing bespoke interventions for early intervention in young adults (the emphasis here). Finally, online therapy as an adjunctive psychosocial treatment for established $B D$ has been tested in a small number of trials, with generally positive findings on at least some outcome measures [e.g., Refs. $(8,9,16,17)]$. Critically, our group has completed an international online trial of mindfulness-based therapy in latestage $\mathrm{BD}$ with no reportable adverse events, providing some confidence about the safety of remote psychotherapy delivery in BD (18).

Arguments for the potential utility of digital delivery of mental health interventions include evidence for comparable effect sizes to face-to-face for many conditions, cost, and access $(6,19)$. Access considerations are particularly compelling in BD because less than half of people on the $\mathrm{BD}$ spectrum worldwide currently receive treatment of any kind (2). In combination with the empirical literature reviewed here, then, it can be concluded that there are strong a priori grounds for developing and testing digital early interventions for BD.

\section{THEORETICAL CONTEXT OF EARLY INTERVENTION IN BIPOLAR DISORDER}

\section{Early Intervention and Stage-Tailoring}

The rationale for early intervention in mental health is well accepted. As reviewed by Arango and colleagues (20), for example, existing research supports two major conclusions: there is increasing evidence for the benefits of universal and selective preventive interventions; and interventions targeting subthreshold presentations (indicated prevention) have potential to improve trajectories. In the domain of BD specifically, Vieta and colleagues recently proposed that early phases of the disorder may be more responsive to treatment and require less aggressive intervention, that there is an "at-risk" mental state for BD that can be used for indicated prevention, and that specific biological, environmental, and dimensional risk factors may be modifiable during this critical window (5).

The call for early intervention in BD overlaps conceptually with interest in stage-tailoring of treatments for BD. Several (largely compatible) clinical staging models have been described to capture the key features of $\mathrm{BD}$ within putative stages. These refer to an initial asymptomatic at-risk stage, followed by a stage characterized by nonspecific symptoms, and then a stage with more specific mood disorder-related, but subsyndromal symptoms. A syndromal stage, usually referred to as clinical stage 2 , then follows, wherein mood episodes meet recognized diagnostic criteria and functional impacts begin to emerge followed by stage 3 , where a repeated pattern of recurrences and relapses is common. The final or end stage (stage 4) is characterized by chronicity manifested by treatment refractoriness and progressively more severe functional impacts. Berk and colleagues (21) highlight the role of accumulating mood episodes and associated functional impairments. A related model proposed by Kapczinski and colleagues (22) prioritizes interepisodic functional and cognitive decrements as BD progresses.

Like the push for early intervention, enthusiasm for the staging approach in BD must be tempered by limited understanding of $\mathrm{BD}$ trajectories [see Ref. (23)]. Indeed, the notion that BD can be understood as a staged disorder is contentious [see Refs. $(24,25)]$. Concerns about the staging heuristic include the potential for unproductive medication use [(26); see also Ref. (27)] and promulgation of the potentially demoralizing neuroprogression hypothesis [see Ref. (28)].2 Such concerns are particularly relevant to those "stages" falling early in the life course, given our incomplete understanding of the long-term effects of mood stabilizers on the developing brain [see Ref. (29)] and the potential to iatrogenically reinforce self-stigma and passivity (30-32).

A consequence of our imperfect developmental understanding of $\mathrm{BD}$ is lack of consensus on the best target population(s) for early intervention (33). Many studies to date have included family history as a risk factor (15), but the positive and negative predictive value of this criterion is limited, and so samples have often been "clinically enriched" by the presence of symptoms. Some research has focused on young people who are already presenting with hypo/manic symptomatology [e.g., Ref. (34)] or a less severe BD diagnosis (35). Research is ongoing to determine which clinical, social, and environmental factors may be associated with the development of BD for those at high familial risk [e.g., Ref. (36)]. The question of to whom should early intervention be offered (and consequently the specific targets of such intervention) has also been influenced by emerging transdiagnostic approaches (discussion later).

\section{Three Principles of Early Intervention: Minimize Harm, Attend to Transdiagnostic and Diagnostic Concerns, and Embrace Teleology}

A tension therefore exists between two face-valid propositions about early intervention in $\mathrm{BD}$-prompt attention to early signs could improve clinical outcomes, but without solid biopsychosocial understandings of disorder trajectories and treatment impacts, we are in danger of causing harm. I believe we can progress by acknowledging three principles of early intervention in BD.

\footnotetext{
${ }^{2}$ I have previously highlighted the dispiriting and unwarranted (cancer-related) terminology currently used in $\mathrm{BD}$ staging research (28). As an alternative to 'stage', we have proposed the term, 'experience with BD'(ranging from limited to substantial) which is both less dispiriting, and avoids unsupported connotations about the nature of BD's trajectory.
} 
First and foremost, early intervention attempts must attend to harm/benefit ratios. Given their more benign side-effect profiles, there is a consensus that any early intervention attempts should therefore privilege psychotherapies over pharmacotherapies [e.g., Ref. (37)]. Pragmatically, it has also been noted that young people are reticent to take medications for even diagnosed mental disorders, and clinicians are reticent to prescribe them (3). On the other hand, there is evidence that delay in instantiating first-line pharmacological treatments for $\mathrm{BD}$ is associated with negative outcomes (38). Taken together, these arguments suggest that interventions with stepped/sequential components may be optimal, with adjunctive medication treatment reserved for those who deteriorate or experience a diagnosable BD episode [for an example of one trial based around these principles, see Ref. (39)]. The focus of the present paper is the first, psychosocial step in this approach.

Secondly, it is useful to recognize a spectrum of specificity of problems/symptoms in populations at risk for $\mathrm{BD}$, ranging for example, from nonspecific anxiety, through sleep/circadian problems, to relatively specific subsyndromal hypomania. In this vein, McGorry and colleagues argue that prevention/early intervention efforts must recognize pervasive pluripotence in psychopathology and so be organized around a broad range of inputs and outputs [e.g., Ref. (33)]. According to the Clinical High At Risk Mental State (CHARMS) (33) paradigm, inputs requiring attention are both disorder specific (family history of diagnosis, subsyndromal states, etc.) and transdiagnostic (e.g., functional decline). Similarly, outputs warranting attention should cover a range of target syndromes and problems. In translation, this paradigm would involve identifying distressed and help-seeking young people and targeting their presenting symptomatology (rather than any particular syndrome or protosyndrome). The term "resilience" does useful work here (40, 41) - such transdiagnostic interventions are designed to address current issues and concomitantly build resilience against a range of negative health outcomes, including onset of frank BD. ${ }^{3}$

Finally, it is critical to expand our thinking beyond a medical paradigm, to explicitly recognize young people as motivated agents. The positive psychology [e.g., Ref. (42)] and recovery paradigms [e.g., Ref. (43)] remind us that a medical focus is only one side of the mental health coin. Complementary priorities are more explicitly teleological [explaining behavior by the outcomes it is intended to achieve, see Ref. (44)] and humanistic [prioritizing positive motivations and agency rather than abnormality and illness, see Ref. (45)] and, as such, will be particularly relevant in engaging young people with early intervention. Developmental psychopathology reminds us that young people at risk of BD are in a particular developmental window, working to optimize their well-being through completion of common developmental tasks [see, e.g., Refs.

\footnotetext{
${ }^{3}$ From a strong transdiagnostic perspective, it might be argued that the population of interest in this paper (young people at risk of BD) does not warrant delineation at all. However, existing literature provides grounds for a hybrid transdiagnostic/ diagnostic approach, and we would be needlessly ignoring (relatively) BD-specific information (the importance of sleep and circadian stability, the ambiguity of elevated mood states, family history of BD diagnosis, etc.) if we adopted a fully diagnosis-blind approach.
}

$(46,47)]$. These theoretical observations have a very pragmatic implication-overlooking young people's subjective quality of life (QoL) and meaning-making motivations will threaten engagement with any intervention we offer $(46,48,49)$. Beyond the aim of improved resilience, then, early intervention can and should support young people building richness into their lives.

In sum, three principles can help navigate tensions between threats and opportunities in early intervention for BD. As we will see later, the various therapeutic targets implied by these principles can be addressed by a hybrid digital intervention drawing from existing evidence-informed psychosocial interventions.

\section{CONSIDERATIONS IN DEVELOPING AN ONLINE INTERVENTION FOR YOUNG PEOPLE AT RISK OF BD}

There is clearly room for innovation in the space of digital early psychosocial intervention for BD. To support the translation of these principles, this section introduces an intervention design framework for future online interventions (Figure 1). It was noted earlier that a variety of subpopulations could be targeted as at risk for $\mathrm{BD}$ : To simplify the present exposition, "at risk" is defined as family history of $\mathrm{BD}$, plus the presence of distress (with or without help-seeking behavior). ${ }^{4}$

Following best practice, the design framework identifies specific, malleable causal factors (see Figure 2), a change mechanism (individual therapies with a recovery focus), and mode of delivery (email-supported web-delivery with social network components). The framework is evidence-informed, insomuch as it synthesises existing $\mathrm{BD}$ research into novel adjunctive psychotherapies $(6,28,52,53)$, technological delivery $(18,54)$, stage-tailoring (9), QoL outcomes (55-57), strengths (49, 58-60), co-design, and community-based participatory research (61). Note that the final level in the framework of Figure $\mathbf{1}$ is co-design with consumers: the aim here is not to present a completed intervention, but to present a framework that can form the foundation of a future co-design process to develop such an intervention. ${ }^{5}$

\section{Personalised Content}

The theoretical review presented above suggests that early intervention for young people at risk of BD should have hybrid targets including symptoms and syndromes linked specifically to $\mathrm{BD}$, common nonspecific distress and problems of stage 1 $\mathrm{BD}$, and also positive goals of QoL, and personally meaningful developmental goals. Summarized in Figure 2 are approaches to achieving these diverse ends using modularized web-based delivery of evidence-based therapy components.

\footnotetext{
${ }^{4}$ The design of an early intervention for BD will depend on the nature and definition of the risk population to which it is offered. The clinical aim of, specifically, preventing transition to $\mathrm{BD}$ in high-risk young people has generated a small literature on quantifying this particular risk [see Refs. $(50,51)$ ].

${ }^{5}$ The co-design process could lead to refinement of the considerations presented here, and different co-design processes could lead to different testable interventions.
} 


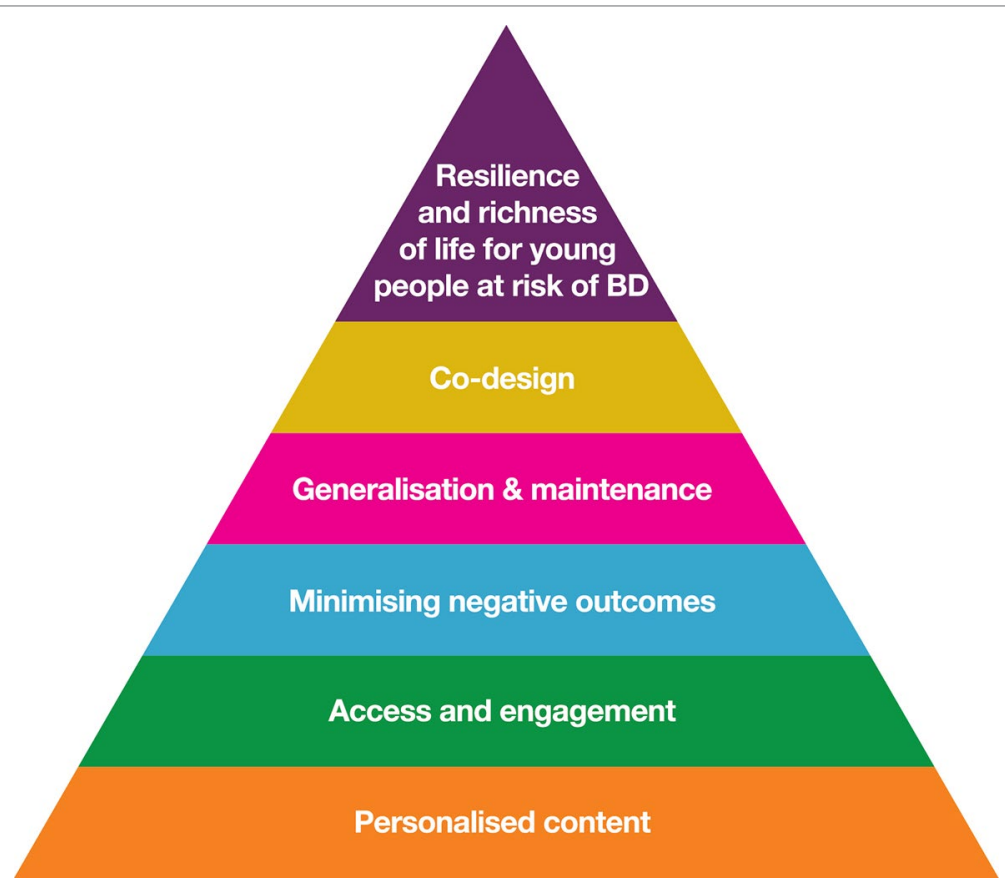

FIGURE 1 | Intervention design framework for feasible, acceptable, and effective online intervention for young people at risk of BD.

A critical target of early intervention attempts is prevention of hypomanic and manic episodes. ${ }^{6}$ Evidence-based therapies for established $\mathrm{BD}$ include development of knowledge and skills around personal relapse triggers and responding early to signs of impending relapse into a mood episode $(62,63)$. In early intervention, this "relapse prevention training" could be repurposed as "hypo/mania onset prevention training" through an interactive psychoeducation online module. Web delivery can also facilitate daily mood monitoring [e.g., via automatic generation of mood charts, see for example, Ref. (18)]. An exciting potential addition to monitoring self-reported mood is the integration of passive objective monitoring of activity via actigraphy (64-66), a technology that will likely be ready for clinical use in the near future. Key to objective monitoring as a clinical tool will be consideration of the human-technology interface: what type of information, in what form, and with what training, is most likely to encourage productive action?

Just as the epidemiology of staging in $\mathrm{BD}$ is unclear, the transdiagnostic symptoms and problems likely to be prevalent in this stage 1 population are not well characterized and differ depending on the operationalization of "at risk." Possible transdiagnostic modules would include psychoeducation related to sleep, drugs and alcohol, physical activity and diet, and mental health stigma. Following the CHARMS approach, we note that this population of young people is heterogeneous, and engagement and efficacy demand the inclusion of optional online modules based on the young person's experience (orange circles in Figure 1). Existing literature suggests that emotion regulation, anxiety, irritability,

\footnotetext{
${ }^{6}$ The most common trajectory in $\mathrm{BD}$ is one or more early depressive episodes, followed by an episode of hypomania or mania that then supports a BD diagnosis.
}

subsyndromal hypomanic, depression, and emotion regulation are likely to warrant attention as optional foci of work.

While diagnostic and transdiagnostic content can be addressed didactically through psychoeducation and cognitive-behavioral therapy, strengths-based content could be addressed through online versions of "third wave psychotherapies" $(28,67)$, with mindfulness and self-compassion strategies having untapped potential for improving QoL in BD (28). The values-based action principles from acceptance and commitment therapy (ACT) $(68,69)$ would be face-valid for encouraging young people to progress through developmental tasks [some of this content can be directed toward the likely strengths in this population, including creativity and a romantic aesthetic, see Ref. (49)].

\section{Access and Engagement}

The great strength, of course, of online intervention is access: the web provides economical access to tailored psychological interventions and can overcome many barriers to accessing psychological assistance for $\mathrm{BD}$, including cost, time, and trust in professionals (6). Online therapies are acceptable to people with established $\mathrm{BD}(70,71)$, and the strengths of digital delivery are particularly pronounced in young adult populations (72).

Contemporary online interventions maximize engagement via best practice persuasive system design [see Refs. $(54,73,74)$ ], including: 1) dialogue support (praise from coach, email reminders, etc.), 2) social support (e.g., moderated forums), and 3) primary task support (modularization of content, personalisation/ monitoring of progress, etc.). We have found that presenting content via brief (2-3 min) "consumer documentary videos" is a powerful engagement strategy [see Ref. (75)]. Other mature 
approaches to digital intervention elevate social network features for their engagement and therapeutic benefits [e.g., Refs. $(72,76)]$.

A major determinant of engagement is duration, and online therapy designers must juggle the desire for comprehensive topic coverage, attrition risk, and patients' preference not to be hurried through content (9). The co-design process is critical for these decisions, with patients' intuitions complemented by their participation in multiple prototype versions. For example, co-design of our intervention for late stage BD (54) led to a structure in which an initial "active phase" with email coaching support lasting 5 weeks; participants then retained access to the site (without coaching support) for the 6 months of follow-up. Based on our retention rates in that trial, we believe that a slightly longer active phase (e.g., the nine weekly content modules proposed in Figure 2) would be feasible and acceptable, but consumer input may modify this prediction.

Finally, intervention design must be sensitive to the fact that the Internet is now most commonly accessed by smartphone, with this device being particularly popular among young people (77, 78). Little is known about how engagement with online therapy content varies by device (79), but not only are smartphones the platform du jour, but they also offer engagement/intervention opportunities not available by website (think ecological momentary assessment and intervention, passive monitoring, etc.). There is reason to think these app-based technologies may be particularly impactful for engagement in young people (14).

\section{Minimizing Risk of and Responding to Clinical Events}

The flexibility and reach of online interventions bring with them concerns about risk management $(18,80)$. We have reported on one successful approach to risk management in online intervention for late-stage BD. Our approach (again, strongly informed by consumer input) explicitly emphasizes patient autonomy and devolution of clinical care to local clinical services (18). A complexity in this strategy is that clinicians overseeing the online therapy may inadvertently come to know about increased risk, requiring some response: we have developed a decision-tree procedure (involving automated and manual components) to address this challenge (54).

Online intervention alone will be insufficient to optimize outcomes for some young people. Stepped care approaches are common in public health [e.g., Refs. (81, 82)], with progression from low- to high-intensity intervention triggered by deterioration/failure to improve. Stepped care has been considered for established BD [see Ref. (83)] and likely has particular relevance in the early intervention context. "Stepping

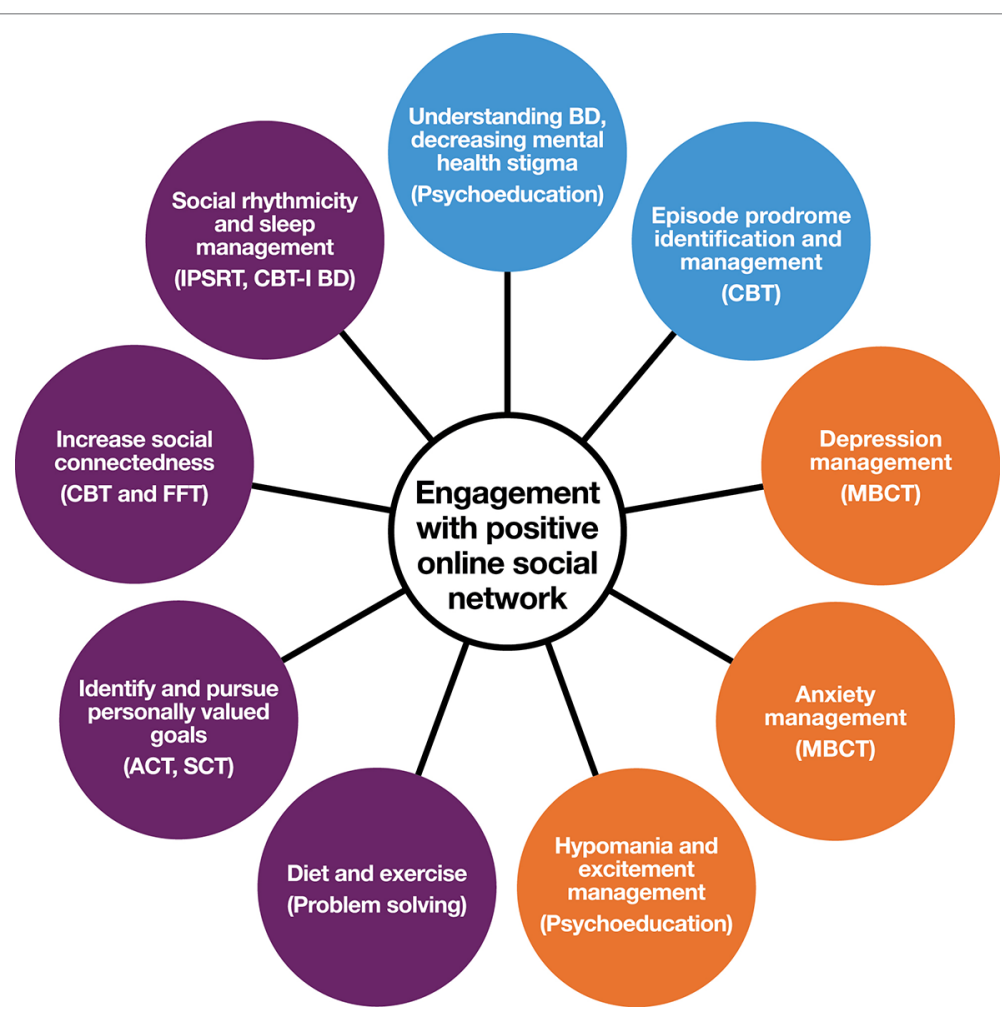

FIGURE 2 | Possible elements of therapeutic content for online early intervention for young people at risk of BD. Blue (BD-specific) and purple (strengths-based targets) are core modules; Orange are optional modules based on young person's current concerns (derived from empirical literature on prevalent problems in high-risk populations, or symptoms elevating risk). CBT, cognitive behavioral therapy; IPSRT, interpersonal and social rhythm therapy; MBCT, mindfulness-based cognitive therapy; ACT, acceptance and commitment therapy; SCT, self-compassion therapy; FFT, family-focused therapy; CBT-I BD, cognitive behavioral therapy for insomnia, modified for BD. 
up" for those not benefiting from digitally delivered psychotherapy could include intensive face-to-face psychotherapy and/or introduction of adjunctive pharmacotherapy (84).

\section{Generalization and Maintenance of Treatment Effects}

A recognized challenge in psychotherapy delivery (whether faceto-face or digital) is generalization of new skills and insights into everyday life. The potential of smartphones to bridge this gap is significant, and a number of groups are investigating apps (either stand-alone or integrated with web-based modules) as part of mobile monitoring and therapy delivery (85-87). It would be unwise to ignore this technological trend in any future early intervention for $\mathrm{BD}$.

Adopting the "active phase"/"follow-up phase" structure described in the section Access and Engagement previously, the follow-up phase, could include periodic booster modules to help maintain therapeutic benefits. Booster modules could provide 1 week of new content, with topics personalized for the individual (based on their preferences, symptoms, and problems remaining at the end of the active phase, etc.).

\section{Co-Design}

Research by our group [e.g., Ref. (61)] confirms the common-sense intuition that participatory research methods (involving end-users in all stages of intervention development) not only circumvents translational barriers but helps accelerate novel treatments by testing theoretical and empirically derived ideas against lived experience (88). Here, the systematic co-design phase would complete pieces of work around therapeutic content (refining Figure 2) and trial and provide feedback on technology prototypes, participate in design of social networking components, etc.

\section{REFERENCES}

1. Australian Bureau of Statistics. National Survey of Mental Health and Wellbeing. Canberra, ACT: Australian Bureau of Statistics (2007).

2. Merikangas KR, Jin R, He JP, Kessler RC, Lee S, Sampson NA, et al. Prevalence and correlates of bipolar spectrum disorder in the world mental health survey initiative. Arch Gen Psychiatry (2011) 68(3):241-51. doi: 10.1001/archgenpsychiatry.2011.12

3. Vallarino M, Henry C, Etain B, Gehue LJ, Macneil C, Scott EM, et al. An evidence map of psychosocial interventions for the earliest stages of Bipolar Disorder. Lancet Psychiatry (2015) 2(6):548-63. doi: 10.1016/ S2215-0366(15)00156-X

4. Bauer M, Andreassen OA, Geddes JR, Vedel Kessing L, Lewitzka U, Schulze TG, et al. Areas of uncertainties and unmet needs in bipolar disorders: clinical and research perspectives. Lancet Psychiatry (2018) 5(11):930-9. doi: 10.1016/S2215-0366(18)30253-0

5. Vieta E, Salagre E, Grande I, Carvalho AF, Fernandes BS, Berk M, et al. Early intervention in bipolar disorder. Am J Psychiatry (2018) 175(5):411-26. doi: 10.1176/appi.ajp.2017.17090972

6. Leitan ND, Michalak EE, Berk L, Berk M, Murray G. Optimizing delivery of recovery-oriented online self-management strategies for bipolar disorder: a review. Bipolar Disord (2015) 17(2):115-27. doi: 10.1111/bdi.12258

7. Gliddon E, Lauder S, Berk L, Cosgrove V, Grimm D, Dodd S, et al. Evaluating discussion board engagement in the MoodSwings online self-help program for bipolar disorder: protocol for an observational prospective cohort study. BMC Psychiatry (2015) 15:243. doi: 10.1186/s12888-015-0630-7

\section{CONCLUSIONS}

I have previously argued that the task of developing online interventions in mental health has little in common with developing face-to-face psychotherapy manuals: Engagement is the sine qua non of digital interventions, and designing an online intervention has much in common with producing a series for Netflix (89). The engagement challenge is particularly pointed in the case of digital natives at risk of, but not diagnosed with, BD. In this population, we cannot assume that "need" is a sufficient driver of engagement, and we must speak to the positive motivations that might lead people to stick with our therapeutic offer. The present perspective paper posits that these engagement-related considerations align neatly with theoretical considerations about early intervention in BD: People at elevated risk of $\mathrm{BD}$ must be viewed through a teleological lens that includes their developmental tasks and opportunities, their current psychological challenges, and their risk of future problems (including diagnosable BD). An evidence-informed intervention design framework is offered as a translational tool to support further work in this important domain.

\section{AUTHOR CONTRIBUTIONS}

GM conceived and wrote the article.

\section{ACKNOWLEDGMENTS}

This project was partly supported by funding from the Barbara Dicker Brain Sciences Foundation, and the National Health and Medical Research Council (APP1102097).

8. Gliddon E, Cosgrove V, Berk L, Lauder S, Mohebbi M, Grimm D, et al A randomized controlled trial of MoodSwings 2.0: an internet-based selfmanagement program for bipolar disorder. Bipolar Disord (2019) 21(1):2839. doi: 10.1111/bdi.12669

9. Murray G, Leitan ND, Berk M, Thomas N, Michalak E, Berk L, et al. Online mindfulness-based intervention for late-stage bipolar disorder: pilot evidence for feasibility and effectiveness. J Affect Disord (2015) 178:46-51. doi: 10.1016/j.jad.2015.02.024

10. Jones S, Wainwright LD, Jovanoska J, Vincent H, Diggle PJ, Calam R, et al. An exploratory randomised controlled trial of a web-based integrated bipolar parenting intervention (IBPI) for bipolar parents of young children (aged 3-10). BMC Psychiatry (2015) 15:122. doi: 10.1186/s12888-015-0505-y

11. Wozney L, Huguet A, Bennett K, Radomski AD, Hartling L, Dyson M, et al. How do eHealth programs for adolescents with depression work? A realist review of persuasive system design components in internet-based psychological therapies. J Med Internet Res (2017) 19(8):e266. doi: 10.2196/jmir.7573

12. Ebert DD, Zarski AC, Christensen H, Stikkelbroek Y, Cuijpers P, Berking M, et al. Internet and computer-based cognitive behavioral therapy for anxiety and depression in youth: a meta-analysis of randomized controlled outcome trials. PLoS One (2015) 10(3):e0119895. doi: 10.1371/journal.pone.0119895

13. Pennant ME, Loucas CE, Whittington C, Creswell C, Fonagy P, Fuggle P, et al. Computerised therapies for anxiety and depression in children and young people: a systematic review and meta-analysis. Behav Res Ther (2015) 67:1-18. doi: 10.1016/j.brat.2015.01.009

14. Hollis C, Falconer CJ, Martin JL, Whittington C, Stockton S, Glazebrook C, et al. Annual research review: digital health interventions for children and 
young people with mental health problems - a systematic and meta-review. J Child Psychol Psychiatry (2017) 58(4):474-503. doi: 10.1111/jcpp.12663

15. Perich T, Mitchell PB. Psychological interventions for young people at risk for bipolar disorder: a systematic review. J Affect Disord (2019) 252:84-91. doi: 10.1016/j.jad.2019.04.058

16. Lauder S, Chester A, Castle D, Dodd S, Gliddon E, Berk L, et al. A randomized head to head trial of MoodSwings.net.au: an internet based self-help program for bipolar disorder. J Affect Disord (2015) 171:13-21. doi: 10.1016/j.jad.2014.08.008

17. Smith DJ, Griffiths E, Poole R, di Florio A, Barnes E, Kelly MJ, et al. Beating bipolar: exploratory trial of a novel Internet-based psychoeducational treatment for bipolar disorder. Bipolar Disord (2011) 13(5-6):571-7. doi: 10.1111/j.1399-5618.2011.00949.x

18. Fletcher K, Foley F, Murray G. Web-based self-management programs for bipolar disorder: insights from the online, recovery-oriented bipolar individualised tool project. J Med Internet Res (2018) 20(10):e11160. doi: 10.2196/11160

19. Griffiths K, Farrer L, Christensen H. The efficacy of internet interventions for depression and anxiety disorders: a review of randomised controlled trials. Med J Aust (2010) 192(Suppl. 11):S4-S11. doi: 10.5694/j.1326-5377.2010. tb03685.x

20. Arango C, Diaz-Caneja CM, McGorry PD, Rapoport J, Sommer IE, Vorstman JA, et al. Preventive strategies for mental health. Lancet Psychiatry (2018) 5(7):591-604. doi: 10.1016/S2215-0366(18)30057-9

21. Berk M, Hallam KT, McGorry PD. The potential utility of a staging model as a course specifier: a bipolar disorder perspective. J Affect Disord (2007) 100(1-3):279-81. doi: 10.1016/j.jad.2007.03.007

22. Kapczinski F, Dias VV, Kauer-Sant'Anna M, Frey BN, Grassi-Oliveira R, Colom F, et al. Clinical implications of a staging model for bipolar disorders. Expert Rev Neurother (2009) 9(7):957-66. doi: 10.1586/ern.09.31

23. Duffy A, Goodday S, Keown-Stoneman C, Grof P. The emergent course of bipolar disorder: observations over two decades from the canadian high-risk offspring cohort. Am J Psychiatry (2018) appiajp201818040461. doi: 10.1176/ appi.ajp.2018.18040461

24. McGorry PD, Ratheesh A, Berk M, Conus P. Is "early intervention" in bipolar disorder what it claims to be?' Malhi et al. Bipolar Disord (2018) 20(3):181-3. doi: 10.1111/bdi.12641

25. Malhi GS, Morris G, Hamilton A, Outhred T, Mannie Z. Is "early intervention" in bipolar disorder what it claims to be? Bipolar Disord (2017) 19(8):627-36. doi: 10.1111/bdi.12576

26. Malhi GS, Outhred T, Hamilton A, Morris G, Mannie Z. Early intervention in bipolar disorder is not what it claims to be! Bipolar Disord (2018) doi: 10.1111/bdi. 12667

27. Correll CU, Detraux J, De Lepeleire J, De Hert M. Effects of antipsychotics, antidepressants and mood stabilizers on risk for physical diseases in people with schizophrenia, depression and bipolar disorder. World Psychiatry (2015) 14(2):119-36. doi: 10.1002/wps.20204

28. Murray G, Leitan ND, Thomas N, Michalak EE, Johnson SL, Jones S, et al. Towards recovery-oriented psychosocial interventions for bipolar disorder: quality of life outcomes, stage-sensitive treatments, and mindfulness mechanisms. Clin Psychol Rev (2017) 52:148-63. doi: 10.1016/j. cpr.2017.01.002

29. Lawrie SM. Are structural brain changes in schizophrenia related to antipsychotic medication? A narrative review of the evidence from a clinical perspective. Ther Adv Psychopharmacol (2018) 8(11):319-26. doi: $10.1177 / 2045125318782306$

30. Latalova K, Ociskova M, Prasko J, Kamaradova D, Jelenova D, Sedlackova Z. Self-stigmatization in patients with bipolar disorder. Neuro Endocrinol Lett (2013) 34(4):265-72.

31. Michalak E, Livingston JD, Hole R, Suto M, Hale S, Haddock C. 'It's something that I manage but it is not who I am': reflections on internalized stigma in individuals with bipolar disorder. Chronic Illn (2011) 7(3):209-24. doi: $10.1177 / 1742395310395959$

32. Morris E, Hippman C, Murray G, Michalak EE, Boyd JE, Livingston J, et al. Self-stigma in relatives of people with mental illness scale: development and validation. Br J Psychiatry (2018) 212(3):169-74. doi: 10.1192/bjp.2017.23

33. McGorry PD, Hartmann JA, Spooner R, Nelson B. Beyond the "at risk mental state" concept: transitioning to transdiagnostic psychiatry. World Psychiatry (2018) 17(2):133-42. doi: 10.1002/wps.20514
34. Lambert M, Niehaus V, Correll C. Pharmacotherapy in children and adolescents at clinical-high risk for psychosis and bipolar disorder. Pharmacopsychiatry (2016) 49(6):229-44. doi: 10.1055/s-0042-116668

35. Fristad MA, Young AS, Vesco AT, Nader ES, Healy KZ, Gardner W, et al. A randomized controlled trial of individual family psychoeducational psychotherapy and omega-3 fatty acids in youth with subsyndromal bipolar disorder. J Child Adolesc Psychopharmacol (2015) 25(10):764-74. doi: 10.1089/cap.2015.0132

36. Hartmann JA, Nelson B, Ratheesh A, Treen D, McGorry PD. At-risk studies and clinical antecedents of psychosis, bipolar disorder and depression: a scoping review in the context of clinical staging. Psychol Med (2019) 49(2):177-89. doi: 10.1017/S0033291718001435

37. Pfennig A, Correll CU, Marx C, Rottmann-Wolf M, Meyer TD, Bauer M, et al. Psychotherapeutic interventions in individuals at risk of developing bipolar disorder: a systematic review. Early Interv Psychiatry (2014) 8(1):311. doi: 10.1111/eip.12082

38. Drancourt N, Etain B, Lajnef M, Henry C, Raust A, Cochet B, et al. Duration of untreated bipolar disorder: missed opportunities on the long road to optimal treatment. Acta Psychiatr Scand (2013) 127(2):136-44. doi: 10.1111/j.1600-0447.2012.01917.x

39. Nelson B, Amminger GP, Yuen HP, Wallis N, JK M, Dixon L, et al. Staged treatment in early psychosis: a sequential multiple assignment randomised trial of interventions for ultra high risk of psychosis patients. Early Interv Psychiatry (2018) 12(3):292-306. doi: 10.1111/eip.12459

40. Southwick SM, Charney DS. The science of resilience: implications for the prevention and treatment of depression. Science (2012) 338(6103):79-82. doi: 10.1126/science. 1222942

41. Commonwealth of Australia. A national framework for recovery-oriented mental health services: policy and theory. Australian Health Ministers Advisory Council, editor. Canberra: Commonwealth of Australia (2013). p. 1-43.

42. Wood AM, Tarrier N. Positive clinical psychology: a new vision and strategy for integrated research and practice. Clin Psychol Rev (2010) 30(7):819-29. doi: 10.1016/j.cpr.2010.06.003

43. Tse S, Murray G, Chung KF, Davidson L, Ng KL, Yu CH. Exploring the recovery concept in bipolar disorder: a decision tree analysis of psychosocial correlates of recovery stages. Bipolar Disord (2014) 16(4):366-77. doi: 10.1111/bdi. 12153

44. Juarrero A. Dynamics in action: intentional behavior as a complex system. Cambridge, Massachusetts: The MIT Press (1999). doi: 10.7551/ mitpress/2528.001.0001

45. Vogt H, Ulvestad E, Eriksen TE, Getz L. Getting personal: can systems medicine integrate scientific and humanistic conceptions of the patient? J Eval Clin Pract (2014) 20(6):942-52. doi: 10.1111/jep.12251

46. Cicchetti D. A developmental psychopathology perspective on bipolar disorder. In: Miklowitz D, Cicchetti D, editors. Understanding bipolar disorder: a developmental psychopathology perspective. London: Guilford Publications (2010). p. 1-32.

47. Healy P. DSM diagnosis and beyond: on the need for a hermeneuticallyinformed biopsychosocial framework. Med Health Care Philos (2011) 14(2):163-75. doi: 10.1007/s11019-010-9284-x

48. Miklowitz DJ, Cicchetti D. Toward a life span developmental psychopathology perspective on bipolar disorder. Dev Psychopathol (2006) 18(4):935-8. doi: $10.1017 /$ S0954579406060469

49. Murray G, Johnson SL. The clinical significance of creativity in bipolar disorder. Clin Psychol Rev (2010) 30(6):721-32. doi: 10.1016/j.cpr.2010.05.006

50. Leopold K, Ritter P, Correll CU, Marx C, Ozgurdal S, Juckel G, et al. Risk constellations prior to the development of bipolar disorders: rationale of a new risk assessment tool. J Affect Disord (2012) 136(3):1000-10. doi: 10.1016/j.jad.2011.06.043

51. Correll CU, Olvet DM, Auther AM, Hauser M, Kishimoto T, Carrion RE, et al. The bipolar prodrome symptom interview and scale-prospective (BPSS-P): description and validation in a psychiatric sample and healthy controls. Bipolar Disord (2014) 16(5):505-22. doi: 10.1111/bdi.12209

52. Fletcher K, Yang Y, Johnson SL, Berk M, Perich T, Cotton S, et al. Buffering against maladaptive perfectionism in bipolar disorder: the role of selfcompassion. J Affect Disord (2019) 250:132-9.

53. Yang Y, Fletcher K, Whitehead R, Murray G. Toward new therapeutic mechanisms in bipolar disorder: analog investigation of self-compassion 
and nonattachment to self. Front Psychol (2018) 9:1848. doi: 10.3389/ fpsyg.2018.01848

54. Fletcher K, Foley F, Thomas N, Michalak E, Berk L, Berk M, et al. Web-based intervention to improve quality of life in late stage bipolar disorder (ORBIT): randomised controlled trial protocol. BMC Psychiatry (2018) 18(1):221. doi: 10.1186/s12888-018-1805-9

55. Morton E, Michalak EE, Hole R, Buzwell S, Murray G. 'Taking back the reins' - A qualitative study of the meaning and experience of self-management in bipolar disorder. J Affect Disord (2018) 228:160-5. doi: 10.1016/j.jad.2017.12.018

56. Morton E, Murray G, Michalak EE, Lam RW, Beaulieu S, Sharma V, et al. Quality of life in bipolar disorder: towards a dynamic understanding. Psychol Med (2017). doi: 10.1017/S0033291717002495

57. Morton E, Michalak EE, Murray G. What does quality of life refer to in bipolar disorders research? A systematic review of the construct's definition, usage and measurement. J Affect Disord (2017) 212:128-37. doi: 10.1016/j. jad.2017.01.026

58. Johnson SL, Moezpoor M, Murray G, Hole R, Barnes SJ, Crest BD, et al. Creativity and bipolar disorder: igniting a dialogue. Qual Health Res (2016) 26(1):32-40. doi: 10.1177/1049732315578403

59. Johnson SL, Murray G, Hou S, Staudenmaier PJ, Freeman MA, Michalak EE, et al. Creativity is linked to ambition across the bipolar spectrum. J Affect Disord (2015) 178:160-4. doi: 10.1016/j.jad.2015.02.021

60. Johnson SL, Murray G, Fredrickson B, Youngstrom EA, Hinshaw S, Bass JM, et al. Creativity and bipolar disorder: touched by fire or burning with questions? Clin Psychol Rev (2012) 32:1-12. doi: 10.1016/j.cpr.2011.10.001

61. Michalak EE, Hole R, Livingston JD, Murray G, Parikh SV, Lapsley S, et al. Improving care and wellness in bipolar disorder: origins, evolution and future directions of a collaborative knowledge exchange network. Int J Ment Health Syst (2012) 6:16. doi: 10.1186/1752-4458-6-16

62. Miklowitz DJ, Goodwin GM, Bauer MS, Geddes JR. Common and specific elements of psychosocial treatments for bipolar disorder: a survey of clinicians participating in randomized trials. J Psychiatr Pract (2008) 14(2):77-85. doi: 10.1097/01.pra.0000314314.94791.c9

63. Malhi GS, Bassett D, Boyce P, Bryant R, Fitzgerald PB, Fritz K, et al. Royal Australian and New Zealand College of Psychiatrists clinical practice guidelines for mood disorders. Aust N Z J Psychiatry (2015) 49(12):1087206. doi: $10.1177 / 0004867415617657$

64. Scott J, Murray G, Henry C, Morken G, Scott E, Angst J, et al. Activation in bipolar disorders: a systematic review. JAMA Psychiatry (2017) 74(2):18996. doi: 10.1001/jamapsychiatry.2016.3459

65. Merikangas KR, Swendsen J, Hickie IB, Cui L, Shou H, Merikangas AK, et al. Real-time mobile monitoring of the dynamic associations among motor activity, energy, mood, and sleep in adults with bipolar disorder. JAMA Psychiatry (2018) doi: 10.1001/jamapsychiatry.2018.3546

66. Lyall LM, Wyse CA, Graham N, Ferguson A, Lyall DM, Cullen B, et al. Association of disrupted circadian rhythmicity with mood disorders, subjective wellbeing, and cognitive function: a cross-sectional study of 91 105 participants from the UK Biobank. Lancet Psychiatry (2018) 5(6):50714. doi: 10.1016/S2215-0366(18)30139-1

67. Murray G. Do I have a self? (and other useful questions from Buddhist mindfulness). Aust N Z J Psychiatry (2015) 49(7):593-4. doi: $10.1177 / 0004867415590460$

68. Hayes SC, Luoma JB, Bond FW, Masuda A, Lillis J. Acceptance and commitment therapy: model, processes and outcomes. Behav Res Ther (2006) 44(1):1-25. doi: 10.1016/j.brat.2005.06.006

69. Hayes SC. Acceptance and commitment therapy, relational frame theory, and the third wave of behavioral and cognitive therapies. Behav Ther (2004) 35(4):639-65. doi: 10.1016/S0005-7894(04)80013-3

70. Todd NJ, Jones SH, Lobban FA. What do service users with bipolar disorder want from a web-based self-management intervention? A qualitative focus group study. Clin Psychol Psychother (2013) 20(6):531-43. doi: 10.1002/cpp.1804

71. Todd NJ, Jones SH, Hart A, Lobban FA. A web-based self-management intervention for bipolar disorder 'Living with Bipolar': a feasibility randomised controlled trial. J Affect Disord (2014) 169C:21-9. doi: 10.1016/j.jad.2014.07.027

72. Rice S, Gleeson J, Davey C, Hetrick S, Parker A, Lederman R, et al. Moderated Online Social Therapy (MOST) for depression relapse prevention in young people: pilot study of a 'next generation' online intervention. Early Interv Psychiatry. (2016). doi: 10.1111/eip.12354
73. Kelders SM, Kok RN, Ossebaard HC, Van Gemert-Pijnen JEWC. Persuasive system design does matter: a systematic review of adherence to web-based interventions. J Med Internet Res (2012) 14(6):17-40. doi: 10.2196/jmir.2104

74. Lauder S, Chester A, Castle D, Dodd S, Berk L, Klein B, et al. Development of an online intervention for bipolar disorder. Psychol Health Med (2013) 18(2):155-65. doi: 10.1080/13548506.2012.689840

75. Georgy N. A Qualitative Exploration of Engagement with Online Interventions. Melbourne, Australia: Swinburne University of Technology (2018).

76. Rice S, Gleeson J, Leicester S, Bendall S, D’Alfonso S, Gilbertson T, et al. Implementation of the enhanced Moderated Online Social Therapy (MOST+) model within a National Youth E-Mental Health Service (eheadspace): protocol for a single group pilot study for help-seeking young people. JMIR Res Protoc (2018) 7(2):e48. doi: 10.2196/resprot.8813

77. Australian Communications and Media Authority. Communications report. Canberra: Australian Government (2018). p. 153.

78. Australian Communications and Media Authority. Communications report 2013-14 series Report 1-Australians' digital lives. Canberra: Australian Government (2015). p. 28.

79. Morrison LG, Geraghty AWA, Lloyd S, Goodman N, Michaelides DT, Hargood C, et al. Comparing usage of a web and app stress management intervention: an observational study. Internet Interv (2018) 12:74-82. doi: 10.1016/j.invent.2018.03.006

80. Cosgrove V, Gliddon E, Berk L, Grimm D, Lauder S, Dodd S, et al. Online ethics: where will the interface of mental health and the internet lead us? Int J Bipolar Disord (2017) 5(1):26. doi: 10.1186/s40345-017-0095-3

81. Cross SP, Hickie I. Transdiagnostic stepped care in mental health. Public Health Res Pract (2017) 27(2). doi: 10.17061/phrp2721712

82. Richards DA, Bower P, Pagel C, Weaver A, Utley M, Cape J, et al. Delivering stepped care: an analysis of implementation in routine practice. Implement Sci (2012) 7:3. doi: 10.1186/1748-5908-7-3

83. Parikh SV. Brief versus intensive psychosocial treatments for bipolar disorder: time for stepped care? Am J Psychiatry (2014) 171(12):1335. doi: 10.1176/appi.ajp.2014.14070887

84. Salvadore G, Drevets WC, Henter ID, Zarate CA, Manji HK. Early intervention in bipolar disorder, part II: therapeutics. Early Interv Psychiatry (2008) 2(3):136-46. doi: 10.1111/j.1751-7893.2008.00072.x

85. Faurholt-Jepsen M, Vinberg M, Christensen EM, Frost M, Bardram J, Kessing LV. Daily electronic self-monitoring of subjective and objective symptoms in bipolar disorder-the MONARCA trial protocol (monitoring, treatment and prediction of bipolar disorder episodes): a randomised controlled singleblind trial. BMJ Open (2013) 3(7). doi: 10.1136/bmjopen-2013-003353

86. Gliddon E, Barnes SJ, Murray G, Michalak EE. Online and mobile technologies for self-management in bipolar disorder: a systematic review. Psychiatr Rehabil J (2017) 40(3):309-19. doi: 10.1037/prj0000270

87. Bush NE, Skopp N, Smolenski D, Crumpton R, Fairall J. Behavioral screening measures delivered with a smartphone app: psychometric properties and user preference. J Nerv Ment Dis (2013) 201(11):991-5. doi: 10.1097/ NMD.000000000000039

88. Michalak EE, Barnes SJ, Berk L, Berk M, Jones S, Hole R, et al. Commentary: harnessing the potential of community-based participatory research approaches in Bipolar Disorder. Int J Bipolar Disord (2016) 4(4):1-9. doi: 10.1186/s40345-016-0045-5

89. Murray G, Leitan L, Berk M, Thomas N, Michalak E, Berk L. Online mindfulness-based intervention for late stage bipolar disorder: opportunities and challenges. The 18th Annual Conference of the International Society for Bipolar Disorders; Amsterdam: International Society for Bipolar Disorders. (2016).

Conflict of Interest Statement: The author declares that the research was conducted in the absence of any commercial or financial relationships that could be construed as a potential conflict of interest.

Copyright (®) 2019 Murray. This is an open-access article distributed under the terms of the Creative Commons Attribution License (CC BY). The use, distribution or reproduction in other forums is permitted, provided the original author(s) and the copyright owner(s) are credited and that the original publication in this journal is cited, in accordance with accepted academic practice. No use, distribution or reproduction is permitted which does not comply with these terms. 